\title{
BIODIVERSITY OF FISHES IN CANADA'S NATIONAL CAPITAL REGION
}

\author{
Brian W. COAD* \\ Canadian Museum of Nature, Ottawa, Ontario, Canada
}

Coad B.W. 2011. Biodiversity of fishes in Canada's National Capital Region. Acta Ichthyol. Piscat. 41 (2): 89-94.

Background. Fishes are important both economically and as indicators of environmental health. Questions on the health of aquatic habitats, on the potential effects of planned and accidental changes to the environment, and on the utility of adding sport and other fishes to a water body are best answered by an analysis which is known to be sensitive to changes.

Materials and methods. As an initial test study I examined 107 fish species in and around the National Capital Region of Canada (50 km radius of the Peace Tower at the Parliament Buildings) in terms of 56 parameters. The parameters include life history characteristics such as size, lifespan, breeding season, egg numbers, and feeding, as well as zoogeographic origins, distribution, and risk status. Non-parametric tests and a logistic regression were used to analyze the data.

Results. A test case comparison of sport versus non-sport fishes confirmed the empirical observation that sport fishes are predominately large piscivores. Critical parameters for threatened versus non-threatened species included piscivory and egg production, for present versus absent species feeding habits and refugial origin, and for refugial origin parameters associated with spawning.

Conclusion. The parameter database can be of potential use to determine which species are at risk and which parameters are critical, why certain species are absent, and what parameters characterize sport fishes. The analysis forms a preliminary basis for more detailed field studies which can then be directed to specific life history traits and environmental variables.

Keywords: Biodiversity, fishes, life history, environment, Canada

\section{INTRODUCTION}

The National Capital Region (NCR) of Canada is an area with a radius of $50 \mathrm{~km}$ centred on the Peace Tower of the Parliament Buildings. This circular region has been surveyed for various taxa including fishes (McAllister and Coad 1975). The NCR straddles the Ottawa River and includes a diverse array of habitats from protected waters in Gatineau Park to farmland and heavily urbanised sections. Population growth and development will inevitably constrain the diversity of fishes found in the NCR. Invasion of exotic species, such as zebra mussels, are also a potential threat to the health of fish populations and to the biodiversity. Many species are at the northern limits of their range in this part of Canada and survival of populations for some species is delicately poised with risk intimately associated with life history traits.

The purpose of this study is to use known life history traits and distributional data to explore reasons for the composition of the ichthyofauna. For example, threatened species are compared with those which are well established and these two groups should exhibit different life history traits. Threatened species are often characterised as large and long-lived or $k$-selected. Such species often have a low fecundity, extended age to maturity, and slow growth, rendering them susceptible to man-made change such as habitat destruction, eutrophication, and competition with exotics (Parent and Schriml 1995). Large size attracts interest as food or sport fishes, often leading to overfishing and subsequent stock declines. A migratory phase in the life cycle is suspected to be a critical factor since dams, bridges and roads, farming, pollution, and urbanisation may affect these species by reducing available reproductive habitat or access to it. Threatened species may have other life history traits which constrain them such as a preference for colder water, a declining asset when forest is cleared and urban wastes raise temperature levels. Similarly, specialised feeders such as predators at the top of the food chain are likely to be more at risk than omnivores. Successful species, on the other hand, are more likely to be small, short-lived and $r$-selected, able to adapt or recover from man-made changes through annual production of many young. Nestbuilders and species showing parental care may also be more successful in bringing more young through earlier stages of development.

The National Capital Region was covered by an ice sheet 12000 years BP and has been recolonised since

\footnotetext{
${ }^{*}$ Correspondence: Dr. Brian W. Coad, Canadian Museum of Nature, P.O. Box 3443, Station D, Ottawa, Ontario, Canada K1P 6P4, phone: +001 (613) 364-4067, e-mail:bcoad@mus-nature.ca
} 
then. However a number of species are found in neighbouring areas but not within the Region. The life history traits of these species are compared. The species entered the NCR primarily from a Mississippian or an Atlantic refugium and these two are compared also.

The life history traits of sport and non-sport species were determined as a test of the methodology. Sport fishes are expected to be large piscivores, given the known preferences of anglers in North America. Most fishermen use spoons, plugs, and live baits, that is active rather than passive means to catch fishes and these naturally take fast-moving, visually feeding piscivores. Other, quite large species such as common carp (Cyprinus carpio) and various other large cyprinids and catostomids are not sought after by anglers, these fishes being bottom feeders using tactile and olfactory cues and not usually active pursuers of moving bait.

Comparisons of exotic and native species were also attempted but the number of exotic species was too limited for statistical analyses.

\section{MATERIALS AND METHODS}

The species composition of the National Capital Region and neighbouring areas was determined from literature and field records of the Canadian Museum of Nature, Ottawa (Table 1, Fig. 1). Taxa were recorded to species level only, with the exception of Esox americanus for which both subspecies, americanus and vermiculatus, were included. Literature sources were McAllister and Coad (1975), Lee et al. (1980), Coad (1983, 1985, 1986, 1987a), Bernatchez and Giroux (1991), Page and Burr (1991), and Mandrak and Crossman (1992).

Life history traits were determined from original literature on each species and literature sources which summarise extensive studies on the species under consideration. The prime sources were Scott and Crossman (1973), Becker (1983), Hénault and Fortin (1994), and Coad et al. (1995).

The data matrix comprises life history traits which are summarised in Table 2 (online resource ${ }^{* *}$ ). Other elements in the matrix scored for each species are whether the fish is a sport species, an exotic, its refugium origin in the last glaciation (Mississippian, Atlantic, or boreal), distribution in relation to the National Capital Region (range from one compass direction to all compass directions, i.e., occurs North, South, East, and West of the NCR), status (threatened or common or non-threatened; based on field data such as Coad (1987a), the summary work of McAllister et al. (1985), and reports of the Committee on the Status of Endangered Wildlife in Canada (COSEWIC) (Campbell 1994), the absence of species from the NCR but found within a $200 \mathrm{~km}$ radius centred on the NCR (Coad 1987b), and significance (number of Canadian territories and provinces the species occurs in, including introductions).

Analyses comprised the whole data set when presence/absence was compared, excluded species not recorded in the NCR for the threatened/non-threatened and sport/non-sport comparisons, and excluded exotics and species not recorded for the NCR for refugia compar- isons. Comparisons of exotic and native species were also attempted but the number of exotic species was too limited for statistical analyses.

Analyses were carried out using the SAS (Anonymous 1990) and SYSTAT (Wilkinson 1990) statistical packages. Nonparametric tests were used (Kruskal-Wallis one-way analysis of variance and the Mann-Whitney $U$-test statistic) and a logistic regression (Parent and Schriml 1995). The logistic procedure fits linear regression models for binary (presence, absence) or ordinal data (e.g., small, medium, large) by the method of maximal likelihood (Anonymous 1990). The logistic procedure was used with the stepwise option, the logit link function, and with a significance level of 0.05 for entry or staying in the model. The dependent variable was, for example, fish status (threatened $=1$ or non-threatened $=2$ ) and the independent variables were the life history traits. The linear logistic equation or model takes the form:

$$
\operatorname{logit}(P)=\log (P /(1-P)=\alpha+\beta x
$$

where $P=$ is the response probability of status $=1$, $\alpha=$ is the intercept parameter, $\beta=$ the vector or slope parameter, and $x=$ the vector of explanatory variables. The best model defining the differences between the various pairs tested is given based on concordance and the -2 Log Likelihood criterion.

Specimens for this study were collected under licences from the Ontario Ministry of Natural Resources, the Ministère des Ressources naturelles et de la Faune and the National Capital Commission.

\section{RESULTS}

A total of 74 species were found to occur within the National Capital Region. In areas around the Region 33 species are recorded as being present but have not been caught or recorded in the NCR as evidenced by voucher specimens (Coad 1987b; Table 1). Four species are listed as exotics (not found naturally in the Atlantic drainage of Canada) but they are included within the total for the Region.

The distribution maps (Figs. 1-6) show variability in presence attributed to several factors, e.g., Salvelinus fontinalis is constrained by temperature being mostly absent south of the Ottawa River in flat farm land and urban areas but concentrated north of the river in the cooler, forested Gatineau Hills.

The test case comparison of sport versus non-sport within the NCR fishes showed that the significant variables $(P<0.05)$ on the Kruskal-Wallis analysis were exotic status, length, age at maturity, life span, feeding in schools, piscivory, feeding in rivers, egg numbers and size, number of spawning seasons, and status. The principal exotic species are sport fishes (Table 1, three salmonids, regularly stocked), sport fishes live longer, grow larger, have a later age for maturity and more breeding seasons than small, short-lived non-sport species, sport fishes are mainly piscivores and are often solitary, 
feeding in rivers and lakes rather than smaller habitats with fewer prey species, egg numbers are higher and egg size is larger in sport fish as a match to body size, and sport fishes do not have a threatened status in the NCR.

The logistic procedure gave the equation:

$$
\operatorname{logit}(P)=5.58-0.022(\mathrm{~L})-4.20(\mathrm{PS})
$$

where: $\mathrm{L}=$ length; $\mathrm{PS}=$ piscivore; with a concordance of $94.7 \%, P<0.0001$ and $-2 \log L=39.11$. This result confirms the empirical observation that sport fish are primarily piscivores and that as length increases then fish are more likely to be sought after by anglers.

The comparison of threatened and non-threatened species was carried out for fishes within the NCR, excluding those species in neighbouring regions not recorded for the NCR. Variables which were significantly different between threatened and non-threatened species were Mississippian refugium origin (more species are from this refugium), sport species (none listed as threatened), feeding level, spawning depth, spawning locality (threatened fish are less likely to be surface feeders, more likely to spawn in deep water, and more likely to spawn in the sea; these latter two are weak associations based on only a single species), and distribution in relation to the NCR and significance in Canada. The logistic procedure gave the equation:

$\operatorname{logit}(P)=4.89-3.29(\mathrm{PSC})+0.0013(\mathrm{NE})-2.10(\mathrm{DS})$

where: $\mathrm{PS}=$ piscivore; $\mathrm{NE}=$ number of eggs; $\mathrm{DS}=$ distribution; with a concordance of $90.5 \%, P<0.0001$ and -2 $\log L=36.01$.

This indicates that piscivores are less likely to be at risk than those species feeding on other foods, fish with a wide distribution are less likely to be at risk, and fish that produce many eggs are more likely to be at risk.

The comparison of presence versus absence of species for the NCR and immediately surrounding areas gave the following results. Significant variables were those related to refugial origin (fish absent from the NCR are more likely to have an origin from a boreal refugium than an Atlantic or Mississippian refugium compared to species present in the NCR), habitat (fish present are more likely to feed in lakes, over sand and in shallow water) distribution (fish present are more widely distributed) and status (fish present are less likely to be threatened). The logistic procedure gave the equation:

$\operatorname{logit}(P)=2.41-3.16(\mathrm{MR})-3.38(\mathrm{AR})+2.24(\mathrm{FD})-1.80(\mathrm{FOS})$

where: $\mathrm{MR}=$ Mississippian refugium; $\mathrm{AR}=$ Atlantic refugium; FD = feeding depth; FOS = feeds over sand; with a concordance of $86.3 \%, P<0.0001$ and $-2 \log L=76.66$.

This indicates that fish feeding in shallow water over sandy substrates are more likely to be present and that fish from either an Atlantic or a Mississippian refugium are more likely to be present.

The comparison of refugial origin gave the following results. Significant variables in addition to the refugia were feeding over gravel (species from the Mississippian, Atlantic, and boreal refugia were more likely to feed over gravel than not), threatened status (fewer species were threatened than not threatened in each refugium, range $11 \%-22 \%$, the highest value being for Atlantic refugium fishes), and significance in terms of presence in territories and provinces (species from Atlantic and boreal refugia have wider distributions in Canada than those from the Mississippian refugium). The logistic procedure gave the equation:

$$
\operatorname{logit}(P)=4.89-0.51(\text { SDur })+1.52(\text { SoMS })
$$

where: SDur = spawning duration; SoMS = spawns over $\mathrm{mud} / \mathrm{silt}$; with a concordance of $64.5 \%, P<0.01$ and $-2 \log L=126$.

This indicates that as length of the spawning season increases then the fish is less likely to have come only from a Mississippian refugium and fish that prefer mud/silt substrates for breeding are less likely to have come only from a Mississippian refugium. Note that this analysis is somewhat awkward because there is third alternative to the Atlantic and Mississippian refugia, i.e., fish may have entered the NCR from both refugia; as a variable increases a fish is less likely to come from a Mississippian refugium but more likely to come from both refugia.

\section{DISCUSSION}

A number of factors were suggested in the Introduction as characteristic of threatened fishes. These factors were large size (with corollary factors such as long life, slow maturation and low fecundity), a migration phase in the life cycle, preference for cooler waters and predatory behaviour. However the results show these assumptions were mostly unfounded-large predators are not threatened in the NCR, a migratory phase and preference for cooler waters was only weakly associated, and low fecundity was less risky.

The presence versus absence comparison reveals a number of historical events which appear to have governed occurrence of species in the NCR. Boreal species are probably at a disadvantage compared to species from southern refugia. The latter are able to survive as local conditions ameliorate naturally after glaciation, aided by warming and eutrophication through the influence of mankind. Widely distributed species are more likely to be present than those narrowly circumscribed. Given the limited area of the NCR, this is only to be expected. Similar areas elsewhere would most likely contain only a subset of the more diverse fauna within the geographic region where they are found. The same argument applies to the result that threatened fish are less likely to be presentthreatened fish are generally less common. Deepwater species are not common in the NCR as there is a lack of readily accessible, large and deep lakes; much of the southern part is farmland. Shallow sandy habitats are common along stream and river margins and in lakes.

Data analyses such as these may be revealing of parameters not intuitively thought to be significant in fish 
Table 1

Ichthyofauna of the National Capital Region (NCR) and areas around the NCR

\begin{tabular}{|c|c|c|c|c|c|c|}
\hline Family & Genera & Species & Natives & Exotics & In NCR & Around NCR \\
\hline Petromyzontidae & 3 & 4 & 4 & 0 & 2 & 2 \\
\hline Acipenseridae & 1 & 2 & 2 & 0 & 1 & 1 \\
\hline Lepisosteidae & 1 & 1 & 1 & 0 & 1 & 0 \\
\hline Amiidae & 1 & 1 & 1 & 0 & 0 & 1 \\
\hline Hiodontidae & 1 & 1 & 1 & 0 & 1 & 0 \\
\hline Clupeidae & 2 & 3 & 3 & 0 & 1 & 2 \\
\hline Anguillidae & 1 & 1 & 1 & 0 & 1 & 0 \\
\hline Esocidae & 1 & $5^{*}$ & $5^{*}$ & 0 & 2 & $3 *$ \\
\hline Umbridae & 1 & 1 & 1 & 0 & 1 & 0 \\
\hline Salmonidae & 5 & 11 & 8 & 3 & 6 & 5 \\
\hline Osmeridae & 1 & 2 & 2 & 0 & 2 & 0 \\
\hline Cyprinidae & 16 & 29 & 28 & 1 & 22 & 7 \\
\hline Catostomidae & 3 & 8 & 8 & 0 & 6 & 2 \\
\hline Ictaluridae & 3 & 6 & 6 & 0 & 6 & 0 \\
\hline Gadidae & 1 & 1 & 1 & 0 & 1 & 0 \\
\hline Percopsidae & 1 & 1 & 1 & 0 & 1 & 0 \\
\hline Fundulidae & 1 & 1 & 1 & 0 & 1 & 0 \\
\hline Atherinidae & 1 & 1 & 1 & 0 & 1 & 0 \\
\hline Moronidae & 1 & 3 & 3 & 0 & 0 & 3 \\
\hline Centrarchidae & 4 & 7 & 7 & 0 & 6 & 1 \\
\hline Percidae & 5 & 10 & 10 & 0 & 8 & 2 \\
\hline Sciaenidae & 1 & 1 & 1 & 0 & 1 & 0 \\
\hline Cottidae & 2 & 4 & 4 & 0 & 1 & 3 \\
\hline Gasterosteidae & 3 & 3 & 3 & 0 & 2 & 1 \\
\hline Totals & 60 & 107 & 103 & 4 & 74 & 33 \\
\hline
\end{tabular}

* includes 2 subspecies, Esox americanus americanus and E. americanus vermiculatus.

distributions. However the data must be examined with whatever the cause, because they are highly productive care since comparisons can be heavily biased owing to the wide variability in life history characters. A prime example of this is egg numbers. Smaller fish generally have fewer eggs than larger fish because a shorter life span limits the energy available for egg production and a reduced body size limits the space for egg accommodation. Sport fish, being larger and longer lived, would be expected to have more eggs than non-sport fish which are generally smaller, but with notable exceptions. If the top three of 57 egg counts for non-sport fish (Acipenser fulvescens, Anguilla rostrata, and Lota lota) are removed from the data set, then the mean falls from 495000 to 41000 . These three species are large and highly productive of eggs. A similar situation is obtained for the comparison of threatened and non-threatened species where fish that produce many eggs are deemed more likely to be at risk, the opposite of the intuitive conclusion. Again, two large and threatened species with many eggs are biasing the analysis. Threatened species generally have fewer eggs than at young ages.

The database (Table 2) can be of potential use to determine which species are at risk and which parameters are critical, why certain species are absent, and what parameters characterize sport fishes. The analysis forms a preliminary basis for more detailed field studies which can then be directed to specific life history traits and environmental variables.

\section{ACKNOWLEDGEMENTS}

I am indebted to numerous summer students over the past 25 years who have collected fishes in the National Capital Region and ordered and indexed a library of reprints on Canadian fishes and their biology. Staff of the former Ichthyology Section also helped to build up a database on Canadian fishes and to catalogue the collections made. Much of the earlier material on which fish distributions are based was collected, identified and catalogued under the curatorship of the late Dr. Don E. McAllister. non-threatened species. Non-threatened species can Judith Busnarda is particularly acknowledged for her recover more quickly from reduction in population size, invaluable work on the computer analyses of the data set 

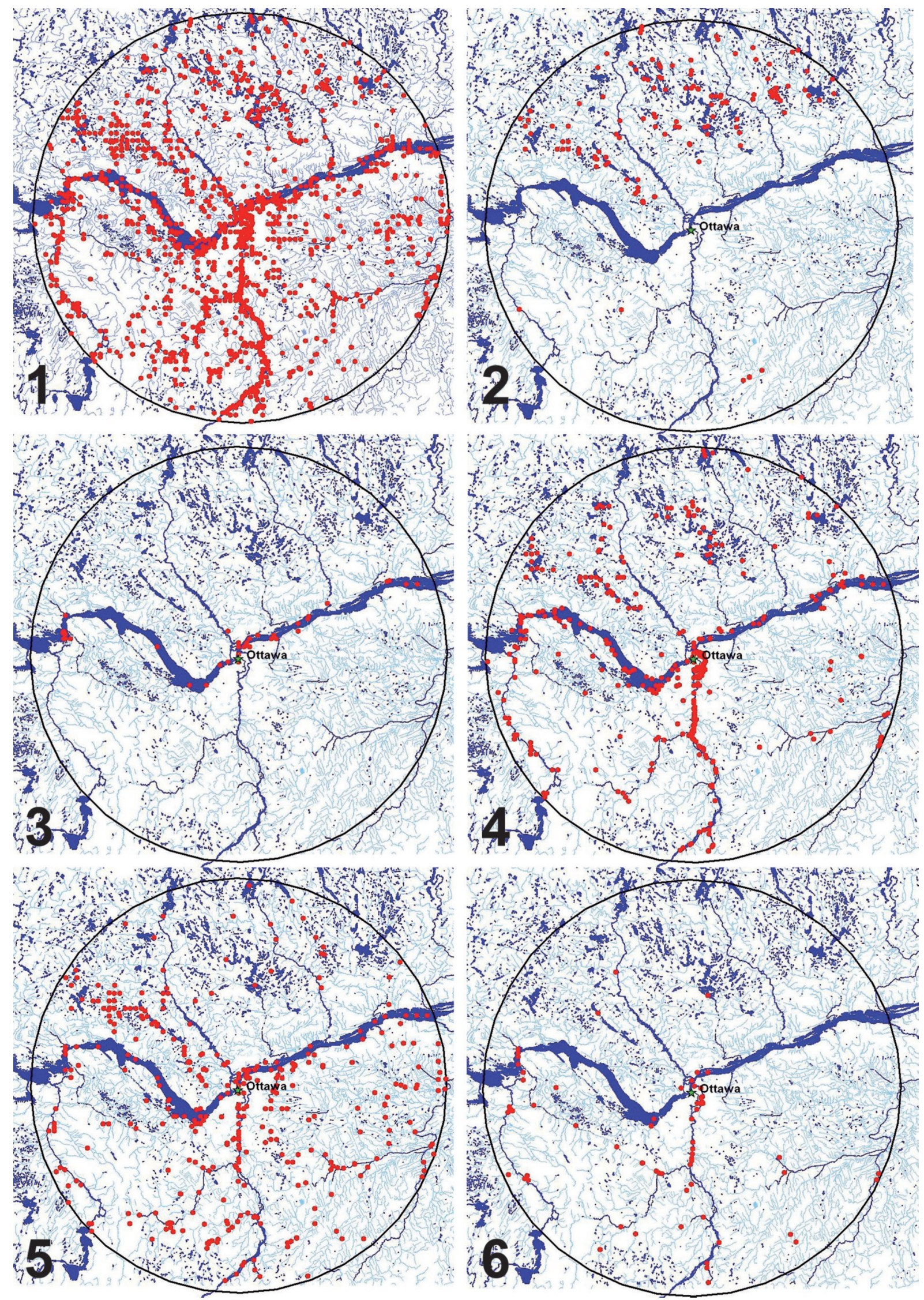

Figs. 1-6. Distribution of five fish species in the Canada's National Capital Region; Fig. 1. All sampled localities; Fig. 2. Salvelinus fontinalis, limited by temperature; Fig. 3. Acipenser fulvescens, a large species highly productive of eggs but threatened through habitat loss; Fig. 4. Micropterus dolomieu, a predator and popular sport fish; Fig. 5. Catostomus commersonii, a common bottom feeder; Fig. 6. Notropis heterodon, a small and short-lived species 
and, through her, Lynn Schriml and Serge Parent of the University of Ottawa who independently set out on a similar study for Great Lakes fishes and whose example provided numerous suggestions for improvement of this manuscript.

\section{REFERENCES}

Anonymous 1990. SAS Technical Report P-200, SAS/STAT Software: CALIS and LOGISTIC Procedures, Release 6.04. SAS Institute Inc., Cary, NC, USA.

Becker G.C. 1983. Fishes of Wisconsin. The University of Wisconsin Press, Madison, WI, USA.

Bernatchez L., Giroux M. 1991. Guide des poissons d'eau douce du Québec. Broquet, La Prairie, Ville de Québec, QC, Canada.

Campbell R.R. 1994. Rare and endangered fishes and marine mammals of Canada: COSEWIC fish and marine mammal subcommittee status reports IX. Canadian Field-Naturalist 107 (1993): 395-401.

Coad B.W. 1983. The alewife, Alosa pseudoharengus (Wilson) a fish new to the National Capital Region (Osteichthyes: Clupeidae). Trail and Landscape 17 (5): 256-258.

Coad B.W. 1985. Out damned spot! Trail and Landscape 19 (2): 76-77.

Coad B.W. 1986. Checklist of the fishes of the Ottawa District. Trail and Landscape 21 (1): 40-60.

Coad B.W. 1987a. The spotfin shiner in the Ottawa District. Trail and Landscape 21 (3): 141-142.

Coad B.W. 1987b. Absent records of fishes in the Ottawa District. Trail and Landscape 21 (5): 249-254.

Coad B.W., Waszczuk H., Labignan I. 1995. Encyclopedia of Canadian fishes. Canadian Museum of Nature, Ottawa and Canadian Sportfishing Productions, Waterdown, ON, Canada.
Hénault M., Fortin R. 1994. Statut de la population de cisco de printemps, Coregonus sp., au lac des Écorces, Québec, Canada. Canadian Field-Naturalist 107 (4): 402-409.

Lee D.S., Gilbert C.R., Hocutt C.H., Jenkins R.E., McAllister D.E., Stauffer J.R. 1980. Atlas of North American freshwater fishes. North Carolina State Museum of Natural History, Raleigh, NC, USA.

Mandrak N.E., Crossman E.J. 1992. A checklist of Ontario freshwater fishes annotated with distribution maps. Royal Ontario Museum Publications in Life Sciences, Toronto, ON, Canada.

McAllister D.E., Coad B.W. 1975. Fishes of Canada's National Capital Region/Poissons de la région de la capitale du Canada. Fisheries Research Board of Canada, Miscellaneous Special Publication 24: 1-200.

McAllister D.E., Parker B.J., McKee P.M. 1985. Rare, endangered and extinct fishes in Canada. Syllogeus 54: 1-192.

Page L.M., Burr B.M. 1991. A field guide to freshwater fishes North America north of Mexico. Houghton Mifflin Company, Boston (Peterson Field Guide Series 42).

Parent S., Schriml L.M. 1995. A model for determination of fish species at risk based upon life-history traits and ecological data. Canadian Journal of Fisheries and Aquatic Sciences 52 (8): 1768-1781. DOI: 10.1139/f95-769.

Scott W.B., Crossman E.J. 1973. Freshwater Fishes of Canada. Bulletin of the Fisheries Research Board of Canada 184. (1979 reprint with supplements).

Wilkinson L. 1990. SYSTAT: The System for Statistics. SYSTAT Inc., Evanston, IL, USA.

Received: 7 July 2009 Accepted: 2 February 2011 Published electronically: 30 June 2011 